\title{
School Participation Empowerment Scale (SPES) Adaptation for Teachers in Malaysia
}

\author{
Suhaili Mohd Yusoff ${ }^{1,2,}$, Tengku Faekah Tengku Ariffin ${ }^{1}$, Mohd Muslim Md Zalli ${ }^{1,3}$ \\ ${ }^{1}$ School of Education and Modern Languages, Universiti Utara Malaysia, 06010 Sintok, Kedah, Malaysia \\ ${ }^{2}$ Scholarship \& Finance Division, Ministry of Education Malaysia, 63000 Cyberjaya, Malaysia \\ ${ }^{3}$ Faculty of Human Development, Universiti Pendidikan Sultan Idris, 35900 Tg. Malim, Perak, Malaysia
}

Received February 2, 2020; Revised March 23, 2020; Accepted March 28, 2020

Copyright $\bigcirc 2020$ by authors, all rights reserved. Authors agree that this article remains permanently open access under the terms of the Creative Commons Attribution License 4.0 International License

\begin{abstract}
Teacher empowerment is increasingly gaining attention among scholars and practitioners across educational contexts due to positive outcomes, especially for school effectiveness in general. Teachers should be empowered to improve their efficiency and professionalism based on their capabilities towards achieving an enhanced teacher workplace and well-being in schools. Therefore, this study validated the measurement model of teacher empowerment as a result of a modification in the School Participation Empowerment Scale (SPES) developed by Short and Rinehart (1992). Three items were removed due to the difference in culture, while 35 of the items were retained and modified. The questionnaires were distributed to 371 respondents using multi-stage sampling. These respondents were secondary school teachers from the state of Kelantan. Confirmatory factor analysis (CFA) in Structural Equation Modelling in AMOS version 24 was employed to assess the fitness of the measurement model. The results showed that fitness indexes achieved the level of acceptance (RMSEA $=.066$, $\mathrm{CFI}=.926, \mathrm{TLI}=.920, \mathrm{ChiSq} / \mathrm{df}=2.611)$. Therefore, this model is suitable for the teacher empowerment construct. This study hopes to be of use in future research on teacher empowerment that could bring further improvement in school effectiveness.
\end{abstract}

Keywords Teacher Empowerment, School Effectiveness, Confirmatory Factor Analysis, Malaysia

\section{Introduction}

The questionnaire is the most accurate measurement tool to measure a latent variable [1]. A questionnaire contains a series of questions called 'items' that can measure the latent variables. The same questionnaire can be used in various industries, such as business management and education. However, the measurement of a construct or variable should be developed based on the cultural perspective within the research area of an intended study [2]. Due to time-saving factors, costs, and human resources, some researchers have adapted and modified existing questionnaires embedded with cultural variances, to incorporate elements related to the topic at hand $[3,4]$. It is not easy to ascertain each of these questionnaires to be appropriate and available to be used in a study even though a construct validity test would have been carried out on the instrument. Hence, an adopted and adapted questionnaire is truly measured based on the interest of different cultures [3]. Confirmatory Factor Analysis (CFA) is, therefore, a statistical method as well as a theory-driven method of analysis that allows measurement models to obtain a construct validity through fitness indexes. Hence, the School Participation Empowerment Scale (SPES) instrument, developed by Short and Rinehart [5], was used for measurement of teachers' empowerment in this study.

The Ministry of Education in Malaysia has been emphasising on decentralisation of teacher empowerment as part of the national school reform since 1992. This pivotal education transformation that involves the role of teachers was further enhanced in the Malaysia Education Blueprint 2013-2025, published by the Ministry of Education, Malaysia. However, the top-down process of policies and implementation is still dominant in this centralised government system [6]. For example, according to the $3 / 1981$ circular that explains the usage of the non-teaching period by teachers in schools, a teacher in a Malaysian public school needs to accomplish his or her tasks and other matters related to the teaching processes during the non-teaching period. There is a disparity between this circular and the original instrument of SPES as one of the items in the dimension of autonomy within the SPES is "I have control over daily schedule" which may 
not match the outcome required in the 3/1981 circular. This situation indicates that not all concepts of empowerment, as initiated from the west, are applicable in the context of teacher empowerment in Malaysia. Abdullah, Almadhoun and Ying [7] have stated that Malaysia is different from the Western cultures in terms of the way empowerment is perceived and interpreted by people in general, and within organisations in particular. Hence, there is a need to modify the SPES further to suit the current context of this study.

Most of the studies on teacher empowerment have been carried out mainly in the western contexts, where the instruments used for these studies were developed by Western researchers in a local context of western teachers as respondents [8]. The question raised from such a situation is whether the instrument that these researchers have used would be appropriate for the Malaysian context. A study by Ali, Abdullah and Mohamed [9] using an adapted SPES instrument showed that the level of teacher empowerment and teacher autonomy being practised in Malaysia is still at a moderate level. Does this finding indicate that the teachers in Malaysia are still not adequately empowered or is it possible that the items used in measuring teacher empowerment are not suitable to the context of teachers in Malaysia?

The adoption of teacher empowerment concept in the teaching and learning process is essential to enable teachers to be more creative and innovative in their teaching practices. This effort is in line with the current educational reforms, apart from providing teachers with the opportunities to develop their potentials and professionalism in their teaching [9]. This study, hence, had adapted the items embedded in SPES instrument. The six dimensions, as stated in the original instrument, were retained. A rigorous process to validate the measurement model of teacher empowerment is imperative for explaining the concept of teacher empowerment based on a Malaysian culture and education system. This process would further assure that the teacher empowerment model can be used as a measurement tool in the pursuit of a more meaningful empirical evidence. Through empowerment, teachers can discover their potentials and develop skills in their professional development [10]. School administration, in particular, needs to have an understanding of the various forms of teacher empowerment that can be practised in schools to maximise student achievement [11].

\subsection{Teacher Empowerment}

There are numerous definitions for teacher empowerment, depending on various researchers. Rappaport [12] argues that it is challenging to define empowerment practices in the form of actions because of the differences in the given contexts. Nonetheless, Yonemura [13] has described the concept of empowerment as a process within the teacher's microcosm, which includes elements of professional development, increased decision making, and collaboration. Maeroff [14] on the other hand, has stated that empowerment is defined as those who are in positions of authority within the school system, with an influence on three key areas which are status, knowledge, and access to decision-making. Levin [15] describes the traditional role of the classroom teacher as almost all of the planning and design [of the curriculum] and is responsible to the district administration as well as educational service specialists.

Meanwhile, Hatcher [16] gives a somewhat different interpretation where it is believed that empowerment is one of the leadership training opportunities that school teachers can adopt by establishing a copy of the hierarchy without collaborative learning. Additionally, the concept of empowerment, as stated by Devos, Tuytens and Hulpia [17], is a form of shared leadership among all members in a group, where teachers can participate in school decision making. Although most researchers have defined teacher empowerment as opportunities and capacities in making decisions within the curriculum as well as in teaching and learning, the definition established by Short and Rinehart [5] encompasses a broader spectrum in understanding the concept of teacher empowerment.

Short and Rinehart [5] define teacher empowerment as a process whereby school participants develop the competence to take charge of their own growth and resolve their own problems. Empowered teachers are likely to have a great sense of ownership in their work, resulting in a greater understanding of responsibility towards their duties as well as their contribution in achieving a win-win situation [8]. Empowerment is observed to be a new method in resolving work-related matters. According to Chan, Rosidih and Khor [18], the aspects of empowerment involve working together in terms of delegating work and power to encourage people to become more involved in making decisions and trusting individuals to have the skills to put their ideas into practices. Teacher empowerment is also perceived as opportunities for shared decision-making, improved professional status, enhancing schools to become a more attractive place for students, building relationships on the principles of trust and creating excellent communication among teachers [10].

The SPES instrument developed by Short and Rinehart [5] is widely used in measuring teachers empowerment [7, 18-21]. An adopted and modified version of the SPES instrument was used in research conducted by Abdullah et al. [7]. Their study, however, had reported that only four dimensions from the SPES instrument were used to measure teacher empowerment in Malaysian context.

\section{Methodology}

For an ethical perspective, one of the most important thing in terms of adaptation and modifications for previous developed instrument is to obtain permission to use from 
relevant parties. Therefore, the researcher has obtained the prior approval from the original author, Professor Dr. Short before the instrumentation process is done [5].

In instrument adaptation, Confirmatory factor analysis (CFA) was performed after completing the exploratory factor analysis (EFA). Exploratory factor analysis provides the researcher with an understanding of the factors (dimensions) that exist in a construct, as well as the variables (items) which are included in each of these factors. The factor loadings of each item showed significance in constructing a factor (dimension). Items with a factor loading result of 0.4 and above would indicate the importance of the items to the construct [22]. This analysis also allows the researcher to confirm or reject the predefined theory through the use of the exploratory factor analysis [22]. Awang, Hui and Zainuddin [23] believe that confirmatory factor analysis is used to determine the dimensions, validity and reliability of a construct. This step further highlights the credibility of the measurement model to affirm that the construct is well developed and validated before it can also be used in the structural equation model.

The validity of the measurement model is evaluated based on the fitness indexes in three categories which are (1) absolute fit, (2) incremental fit and (3) parsimonious fit [22-24]. The absolute fit determines how well the model fits the data sample [25]. This study used the root mean square error of approximation (RMSEA) to examine the absolute fit model. The RMSEA calculates the difference between the covariance sample and the estimated covariance. It shows that the optimal fit parameter is selected from the covariance matrix population [26]. The model is considered fit if the index value is less than 0.08 $[22,23,27]$. Parsimony fit refers to the complexity of the model [28]. A simple model with a better fit should be preferred. The Chi-square or the degrees of freedom (Chisq / df) is an index used to indicate the value of parsimony fit. A good fit index and simple models would show a value that is less than 5.0.

Incremental fit is also known as comparative fit [29] or relative fit indices [25]. It compares the value of Chi-square to the basic model. For these models, the null hypothesis is used that all variables are non-correlated [25]. Comparative fit index (CFI) and Tucker Lewis Index (TLI) are used to derive incremental fit values for the developed model. The model is shown to have a good fit if the CFI and TLI values are higher than 0.90 [30]. This value is to ensure that more stringent filters are used in a model evaluation [30].

\subsection{Respondents}

In this study, multi-stages sampling was used to choose teachers from 17 secondary schools in the state of Kelantan, Malaysia. Questionnaires were distributed to 371 respondents in this study. All the respondents were assured that the data collected were for this research only. Among the respondents, $28.8 \%$ (107) were male and $71.2 \%$ (264) were female. The range for teaching experience of the participants was from 1 year to more than 30 years, while the range of age of the participants was between 20 to more than 50 years old. Demographic information of the respondents is depicted in Table 1 .

Table 1. Demographic data of respondent

\begin{tabular}{|c|c|c|}
\hline Demographic Data & Frequency & Percentage \\
\hline \multicolumn{3}{|l|}{ Gender } \\
\hline Male & 107 & 28.8 \\
\hline Female & 264 & 71.2 \\
\hline \multicolumn{3}{|l|}{ Teaching Experience } \\
\hline$<10$ & 5 & 1.3 \\
\hline $10-20$ & 164 & 44.2 \\
\hline $21-30$ & 184 & 49.6 \\
\hline$>30$ & 18 & 4.9 \\
\hline \multicolumn{3}{|l|}{ Age } \\
\hline $20-30$ & 4 & 1.0 \\
\hline $31-40$ & 58 & 15.6 \\
\hline $41-50$ & 177 & 47.6 \\
\hline$>51$ & 132 & 35.8 \\
\hline
\end{tabular}

\subsection{Measure}

The teacher empowerment constructs, adapted from the SPES, developed by Short and Rinehart [5], were the focus of this study. The back-to-back translation technique, as proposed by Brislin [31], was carried out to translate the questionnaire to ensure that all the participants could understand and answer the items in the instrument. Once the translation process was done, a pre-test was performed before the pilot test was conducted to ensure that an appropriate language level was used to match the targeted group. The result from the pre-test can determine if the participants can easily understand each item in this questionnaire that had been modified. Language use that is easy to understand will positively impact the process of answering the questionnaire, which, in turn, would ensure the validity of the research [1]. The adapted and modified items in this study are presented in Table 2. All items had been tested through the construct validity process. Exploratory factor analysis (EFA) indicated that the 35 items had resulted in a high factor loading, and this result can be retained for the process of construct validity. 
Table 2. Adapted and modified School Participation Empowerment Scale (SPES) using a Malaysian sample

\begin{tabular}{|c|c|c|}
\hline No. & Dimension & Item \\
\hline 1 & Decision Making & I was given the responsibility to monitor school programmes. \\
\hline 2 & Professional Growth & I was given a role that is suited to my skills in school. \\
\hline 3 & Status & I believe I am being respected in school. \\
\hline 4 & Self-Efficacy & I believe I can help students to be independent. \\
\hline 5 & Autonomy & I have an opportunity to request class I want to teach \\
\hline 6 & Impact & I believe I have an ability to get things done. \\
\hline 7 & Decision Making & I was invited to a meeting in deciding an implementation of a new school programme. \\
\hline 8 & Professional Growth & I was treated like a professional. \\
\hline 9 & Status & I believe I'm a very effective teacher. \\
\hline 10 & Self-Efficacy & I believe I can build students' confidence. \\
\hline 11 & Autonomy & I'm teaching my requested subject. \\
\hline 12 & Impact & I joined the staff development programme. \\
\hline 13 & Professional Growth & I have an opportunity to develop my professionalism. \\
\hline 14 & Status & I'm being respected by my colleagues. \\
\hline 15 & Self-Efficacy & I was involved in important programme related to students in school. \\
\hline 16 & Autonomy & I have the freedom to make decisions in teaching techniques. \\
\hline 17 & Impact & I believe my existence can have a positive effect on the school. \\
\hline \multirow[t]{2}{*}{18} & Decision Making & I was involved in making decisions in budgeting. \\
\hline & & (examples: sports day budget and teachers' day budget) \\
\hline 19 & Professional Growth & I work in a school where students are the priority \\
\hline 20 & Status & I was given supported and respected of a colleague \\
\hline 21 & Self-Efficacy & I believe students can learn well during my class. \\
\hline 22 & Autonomy & I decide on my lesson plan. \\
\hline 23 & Decision Making & I was given an opportunity to share my knowledge with other teachers. \\
\hline 24 & Professional Growth & I was given an opportunity to study further \\
\hline 25 & Status & I have a strong knowledge base in my teaching area. \\
\hline 26 & Self-Efficacy & I have an opportunity to sharpen myself through my daily work with students. \\
\hline 27 & Impact & I have a positive influence on other teachers. \\
\hline 28 & Decision Making & The daily activities in the school other than the teaching schedule) are quite flexible. \\
\hline 29 & Professional Growth & I have an opportunity to collaborate with other teachers in school. \\
\hline 30 & Self-Efficacy & I feel that I can make positive changes to my students. \\
\hline 31 & Decision Making & Other teachers asked for my opinion in making decisions. \\
\hline 32 & Status & I believe I'm good at what I do. \\
\hline 33 & Impact & I have a positive impact on other teachers. \\
\hline 34 & Decision Making & My advice was accepted by others. \\
\hline 35 & Decision Making & I have an opportunity to teach other teachers about new ideas. \\
\hline
\end{tabular}




\subsection{Data Analysis}

Analysis of moment structures (AMOS) was used for the SEM to determine the good fit of the teacher empowerment measurement model. Some indexes used in this study included Chi-square, root mean square error of approximation (RMSEA), comparative fit index (CFI) and Tucker Lewis fit index (TLI). The fit index and level of acceptance are shown in Table 3.

\section{Findings of CFA}

Figure 1 shows the CFA results of the good fit indexes and factor loadings for each item that exceeded the value of 0.6 . Thus, all of these items can be retained [22,23].
However, the fitness index of certain items did not meet the level of good fit as determined. The first fitness index showed $(\mathrm{RMSEA}=.09, \mathrm{CFI}=.861, \mathrm{TLI}=.850, \mathrm{ChiSq} / \mathrm{df}$ $=4.006$ ). Therefore, the modification index (MI) needed to be reviewed if there are overlapping or redundant items. Unnecessary items can be identified using the modification index (MI) with a value that is greater than 15 . Similarly, all items that overlap will also result in an MI value that is above 15 . However, the researcher in this study did not modify all the items based on the MI value, but instead, took into consideration the highest MI value. This decision was made for the sole purpose of minimising the modification process for measurement error, whereby once the model has achieved a good fit, the modification process can be stopped $[23,34]$.

Table 3. Index Category and Their Level of Acceptance

\begin{tabular}{|c|c|c|c|}
\hline Name of Category & Index & Level of Acceptance & Proposed by literature \\
\hline \multirow{2}{*}{ Absolute Fit } & Chi-Square & P-value $<0.05$ & {$[32]$} \\
\cline { 2 - 4 } & RMSEA & RMSEA $<0.08$ & {$[30]$} \\
\hline \multirow{2}{*}{ Incremental Fit } & CFI & CFI $>0.9$ & {$[30]$} \\
\cline { 2 - 4 } & TLI & TLI $>0.9$ & {$[33]$} \\
\hline
\end{tabular}
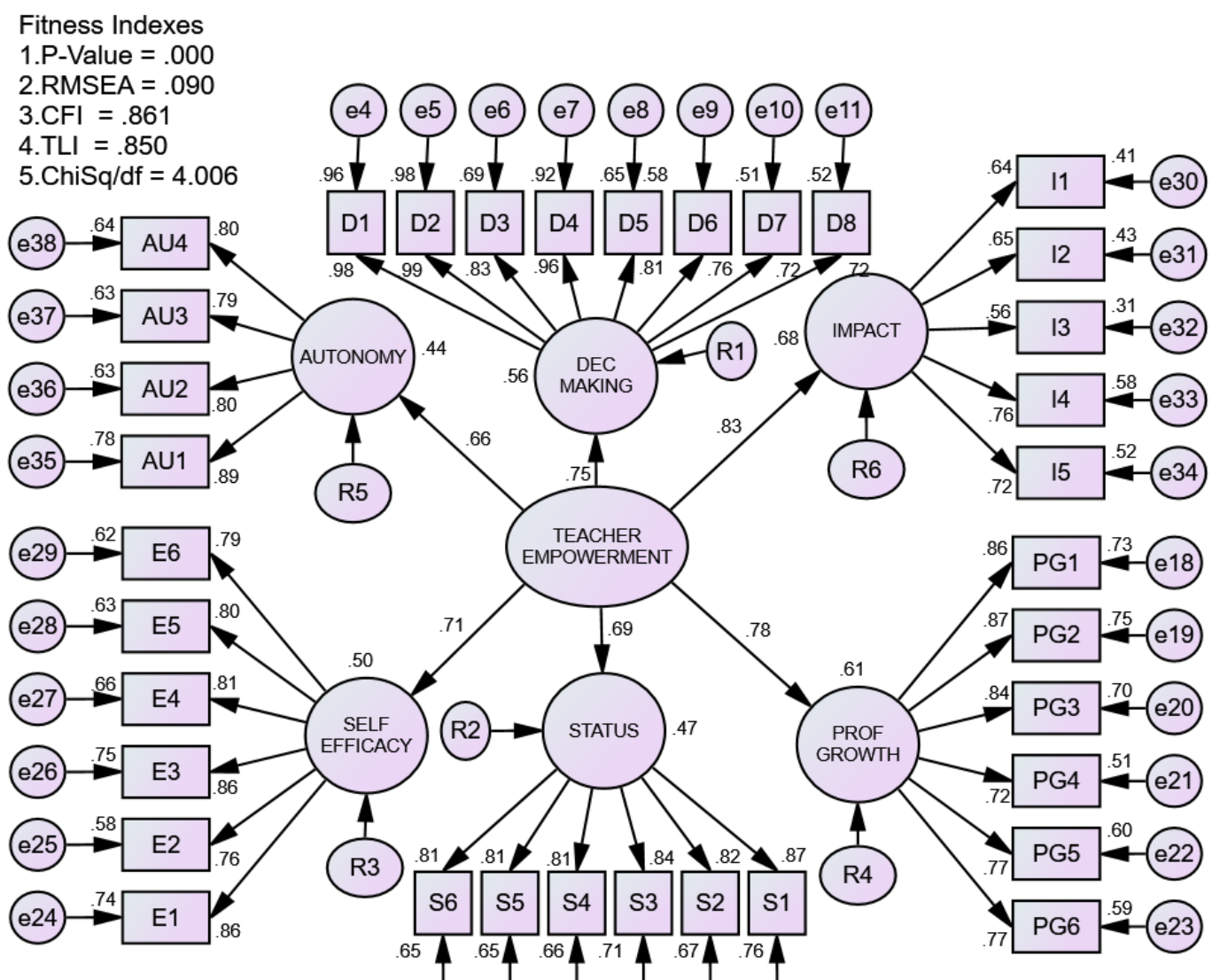

(e17) (e16) (115) (e14) (112)

Figure 1. Measurement Model of Teacher Empowerment with All items Factor Loading 
Table 4 shows the highest and subsequent high value of MI. The correlated measurement error was between e6 <-e8 and e9 <-- e10. The redundant items were between D3-D5 and D6-D7. The researcher decided to set as free parameter estimate for items D3-D5 and D6-D7. The second measurement model was carried out after the modification process was done.

Table 4. Modification Indices (MI)

\begin{tabular}{|c|c|}
\hline Item & Modification Indices (MI) \\
\hline e6 <-- e8 & 111.97 \\
\hline e9<-- e10 & 97.58 \\
\hline
\end{tabular}

Figure 2 shows the second measurement model after the item modification process was performed. The teacher empowerment measurement model was carried out which showed a better fitness index which reached the acceptance level $(\mathrm{RMSEA}=.066, \mathrm{CFI}=.926, \mathrm{TLI}=.920, \mathrm{ChiSq} / \mathrm{df}=$ 2.611). The process in obtaining a good value involved modifying redundant items by setting the relevant item to "free" parameter estimates without deleting any item. This method had successfully retained the existing items while also getting good fit indexes. The summary of the overall fit index is described in Table 5.

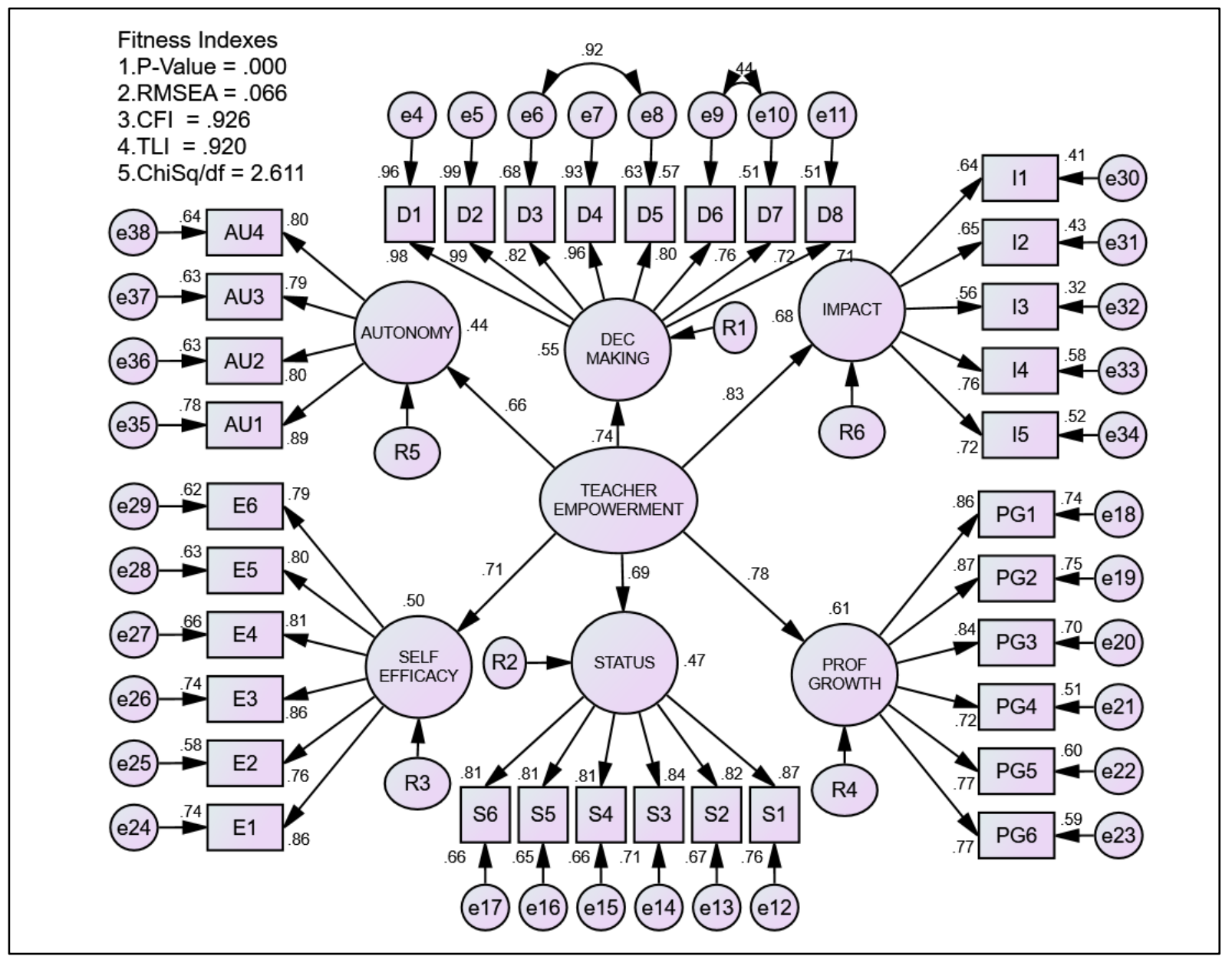

Figure 2. Measurement Model of Teacher Empowerment after Modification

Table 5. Summary for Fitness Indexes

\begin{tabular}{|c|c|c|c|}
\hline Name of Category & Name of Index & Index Value & Conclusion \\
\hline \multirow{2}{*}{ Absolute Fit } & Chi-Square & P-value $<0.05$ & Achieved the required level \\
\cline { 2 - 4 } & RMSEA & RMSEA $<0.08$ & Achieved the required level \\
\hline \multirow{2}{*}{ Incremental Fit } & CFI & CFI $>0.9$ & Achieved the required level \\
\cline { 2 - 4 } & TLI & TLI $>0.9$ & Achieved the required level \\
\hline Parsimonious Fit & Chisq/df & Chi-square/df $<5.0$ & Achieved the required level \\
\hline
\end{tabular}


Table 6. Validity and Reliability Level of Acceptance

\begin{tabular}{|c|c|c|c|}
\hline Category & Index & Level of Acceptance & Suggestions based on LR \\
\hline Convergent Validity & Average Variance Extracted & AVE $>0.5$ & {$[22,23]$} \\
\hline Construct Reliability & Alpha & Alpha $>0.7$ & {$[22,23]$} \\
\hline Composite Reliability & Composite Reliability & CR $>0.6$ & {$[22,23]$} \\
\hline
\end{tabular}

Table 7. Construct Validity and Reliability

\begin{tabular}{|c|c|c|c|c|c|}
\hline Sub-construct & Item & Factor Loading & Cronbach Alpha $>0.7$ & $\mathrm{CR}>0.6$ & AVE $>0.5$ \\
\hline \multirow[t]{9}{*}{ Decision Making } & & & .920 & 0.95 & 0.83 \\
\hline & D1 & .96 & & & \\
\hline & D2 & .99 & & & \\
\hline & D3 & .82 & & & \\
\hline & D4 & .96 & & & \\
\hline & D5 & .80 & & & \\
\hline & D6 & .76 & & & \\
\hline & D7 & .72 & & & \\
\hline & D8 & .71 & & & \\
\hline \multirow[t]{6}{*}{ Impact } & & & .884 & 0.80 & 0.67 \\
\hline & I1 & .64 & & & \\
\hline & $\mathrm{I} 2$ & .65 & & & \\
\hline & $\mathrm{I} 3$ & 56 & & & \\
\hline & I4 & .76 & & & \\
\hline & I5 & .72 & & & \\
\hline \multirow[t]{7}{*}{ Professional Growth } & & & .886 & 0.92 & 0.65 \\
\hline & PG1 & .86 & & & \\
\hline & PG2 & .87 & & & \\
\hline & PG3 & .84 & & & \\
\hline & PG4 & .72 & & & \\
\hline & PG5 & .77 & & & \\
\hline & PG6 & .77 & & & \\
\hline \multirow[t]{7}{*}{ Status } & & & .884 & 0.93 & 0.68 \\
\hline & S1 & .87 & & & \\
\hline & S2 & .82 & & & \\
\hline & S3 & .84 & & & \\
\hline & S4 & .81 & & & \\
\hline & S5 & .81 & & & \\
\hline & S6 & .81 & & & \\
\hline \multirow[t]{7}{*}{ Self-Efficacy } & & & .885 & 0.92 & 0.66 \\
\hline & E1 & .86 & & & \\
\hline & E2 & .76 & & & \\
\hline & E3 & .86 & & & \\
\hline & E4 & .81 & & & \\
\hline & E5 & .80 & & & \\
\hline & E6 & .79 & & & \\
\hline \multirow[t]{5}{*}{ Autonomy } & & & .881 & 0.89 & 0.67 \\
\hline & AU1 & .89 & & & \\
\hline & AU2 & .80 & & & \\
\hline & AU3 & .79 & & & \\
\hline & AU4 & .80 & & & \\
\hline
\end{tabular}


The convergence validity, construct and composite reliability were evaluated once the confirmatory factor analysis had been carried out. The fitness indexes were also obtained to fulfil the unidimensionality requirements. Table 6 shows the results of the level of acceptance for the validity and reliability of all the constructs. Table 7 shows the results of the Average Variance Extracted (AVE) and Composite Reliability (CR) for the teacher empowerment construct. The correlations values for each constructs ranging from 0.40 to $0.70(\mathrm{r}<0.90)$ provide confirmation for discriminant validity [35].

\section{Discussion}

The results showed that all the fitness indexes using the teacher empowerment measurement model had reached the required level of good fit in all three categories. These results were based on the absolute fit category, whereby the RMSEA value was at 0.066 , which was lower than 0.08 , as suggested by [32]. For the incremental fit of this teacher empowerment model, the CFI and TLI values, which needed to be higher than 0.9 , were identified with CFI = 0.926 and TLI $=0.920$. These values were acknowledged as a good fit, as suggested by $\mathrm{Hu}$ and Bentler [30]. The parsimonious fit category was referred to the Chi-square (Chisq/df), whereby the value in this study was at 2.611, which was lower than the determined value of 5.0. Hence, this result indicated that the teacher empowerment model was at an acceptable fitness index. All values of the fit index had proven that the model was acceptable in this study. In terms of the AVE value, which determines the convergent validity and $\mathrm{CR}$ value which determines composite reliability, the model had resulted in a high value for both CR and AVE values. This result further addressed the consistency of the model because the CR value was higher than 0.6 and AVE value was higher than $0.5[22,23]$.

There had been some changes in the operational definition (OD) for the two dimensions in this study, which were autonomy and decision making. However, the six other dimensions highlighted by Short and Rinehart [5] have remained. In the Malaysian context, these two dimensions, as stated, were related to the teaching and learning process in class, whereby the concept of autonomy and decision making are highly emphasised in western countries. It is widely claimed that the dimension of decision making among teachers in the education system of the west involves taking charge of budgets, teacher selection for classes, scheduling and curriculum. At the same time, the dimension of autonomy in the western context refers to the sense of freedom among teachers to make decisions that control certain aspects of their work life. Teachers with autonomy influence scheduling, curriculum, textbooks, and instructional planning [5]. The operational definition for the dimension of professional growth, status, impact and self-efficacy are based on the descriptions by Short and Rinehart [5].

Thus, some of the concepts of teacher empowerment in the Malaysian education context have been redefined in this study based on teachers' perception within the concept of decentralisation in the education system. This new OD is only for the dimensions of decision making and autonomy, as stated below:

Decision-making refers to the participation of teachers in decisions that directly affected their teaching processes such as teaching techniques, job-related work involving budget especially for those who have been appointed as a subject committee and also the implementation of school programmes. This understanding of decision making from the aspect of participation differs from the original OD as defined by Short and Rinehart [5].

Professional Growth refers to teachers' perceptions that the school will provide them with the opportunities to grow and develop as professionals, to learn continuously, and, to expand knowledge and skills through the work-life in school.

Status refers to the teachers' perceptions of professional respect and admiration from colleagues because of their knowledge and expertise in their field.

Self-Efficacy refers to teachers' perceptions of skills and abilities to help students to learn, be competent in building effective programmes for students, and can affect changes in students' learning.

Autonomy refers to the sense of freedom among teachers, especially in managing the teaching processes in the classroom. This sense of freedom includes having to teach the subjects and classes that the teachers have requested as well as being able to teach using the strategies and techniques as planned for the lesson or class. The sense of freedom differs from the original OD as defined by Short and Rinehart [5].

Impact refers to the awareness of the teachers that they have an effect and influence on school life. They should have a good sense of their worthiness in their work and that they are competent in their work which results in recognition for their accomplishments.

\section{Conclusions}

The concept of teacher empowerment in the Malaysian context is quite different from the idea of teacher empowerment from western countries. Instrument modification within this study is intended to enable more accurate and meaningful measurement for the Malaysian education context. There are, unfortunately, still some cases of Malaysian teachers unable to make decisions beyond the classroom due to various underlying factors. Teachers are still bound by the rules even when they are given free time in school. These cases are substantial examples that autonomy among teachers is still limited. 
However, the six dimensions highlighted by Short and Rinehart [5] are the most frequently identified dimensions found in studies related to teacher empowerment. Instruments used based on the literature have also measured and identified as many as six of the dimensions of teacher empowerment [36]. Hence, these six dimensions are essential in measuring teacher empowerment.

The present study evaluated the measurement model for the adapted and modified School Participation Empowerment Scale (SPES) from Short and Rinehart [5], using secondary school teachers in Malaysia as a sample. A total of 35 proposed items were successfully retained using the AMOS Software for Structured Equation Model. A good fit index indicated that this measurement model is best used in measuring teacher empowerment using a Malaysian sample. The six dimensions, as proposed by Short and Rinehart [5], had been retained within this study. Therefore, further studies on teacher empowerment within the Malaysian education context are encouraged to use this model to have better and consistent measurement as well as results that can further contribute to empirical evidence.

\section{Acknowledgments}

This study is part of the first authors' PhD studies at the Universiti Utara Malaysia. This study was funded by the Ministry of Education Malaysia under the CBBPDB Scheme.

\section{REFERENCES}

[1] U. Sekaran. (2003). Research Methods for Business: A Skill Building Approach, 4th ed., John Wiley \& Sons, Inc, New York, 2003.

[2] A. J. Marsella. (1978). Thoughts on cross-cultural studies on the epidemiology of depression, Culture, Medicine and Psychiatry, Vol. 2, 343-357, 1978.

[3] M. M. Ali. (2016). Are we asking the same questions in different contexts: Translation techniques in cross-culture studies in science education? Journal of Turkish Science Education, Vol.13, No.1, 31-44, 2016.

[4] K. Hambleton, A. Kanjee. (2005). Increasing the validity of cross-cultural assessments: Use of improved methods for test adaptations, European Journal of Psychological Assessment, Vol. 11, 147-157, 1995.

[5] P. M. Short, J. S. Rinehart. (1992). School participant empowerment scale: Assessment of level of empowerment within the school environment, Educational and Psychological Measurement, Vol. 52, 951-960, 1992.

[6] T. Bush, A. Ng, K. T. Wei, C. Josephine, D. Glover, M. T. Lee. (2019). Dasar Pendidikan di Malaysia: Cabaran Pelaksanaan dan Rundingan Dasar, The Head Foundation: Human Capital \& Education for Asian Development,
Singapore, 2019.

[7] A. G. K. Abdullah, T. Z. Almadhoun, L. L. Ying. (2015). Organizational empowerment and commitment: the mediating effect of psychological empowerment, Asian Journal of Social Sciences, Art and Humanities, Vol. 3, No.2, 1-7, 2015.

[8] E. K. Boey. (2010). Teacher Empowerment in Secondary Schools: A Case Study in Malaysia, Herbert Utz Verlag, Germany, 2010.

[9] A. J. Ali, A. G. K. Abdullah, I. Mohamed. (2019). Amalan pengupayaan dan autonomi guru dalam pembelajaran dan pemudahcaraan abad ke-21, Jurnal Kepimpinan Pendidikan, Vol. 6, No.1, 49-58, 2019.

[10] A. Balyer, K. Özcan, A. Y1ldı. (2017). Teacher empowerment: School administrators' roles, Eurasian Journal of Educational Research, Vol. 70, 1-18, 2017.

[11] Moran, K. H. Larwin. (2017). Building administrator's facilitation of teacher leadership: Moderators associated with teachers' reported levels of empowerment, Journal of Organizational \& Educational Leadership, Vol. 3, No. 1, 2-29, 2017.

[12] J. Rappaport. (1987). Terms of empowerment/exemplars of prevention: Toward a theory for community psychology, American Journal of Community Psychology, Vol. 15, No. 4, 121-148, 1987.

[13] M. Yonemura. (1986). Reflections on teacher empowerment and teacher education, Harvard Educational Review, Vol. 56, No.4, 473-480, 1986.

[14] G. I. Maeroff. (1988). A blueprint for empowering teachers, Phi Delta Kappan, Vol. 62, No.7, 472-477, 1988.

[15] H. Levin. (1991). Building School Capacity for Effective Teacher Empowerment: Applications to Elementary Schools with at-Risk Students, Consortium for Policy Research in Education (ERIC Document Reproduction Service No. 337856), New Brunswick, NJ, 1991.

[16] R. Hatcher. (2005). The distribution of leadership and power in schools, British Journal of Sociology of Education, Vol. 26, No.2, 253-267, 2005.

[17] G. Devos, M. Tuytens, H. Hulpia. (2014). Teachers' organizational commitment: Examining the mediating effects of distributed leadership, American Journal of Education, Vol. 120, 205-231, 2014.

[18] Y. F. Chan, R. Rosidih, M. K. Khor. (2017). The relationship between the practices of leadership style and teacher empowerment of headmasters in the primary schools, Journal of Global Business and Social Entrepreneurship, Vol. 1, No.2, 56-68, 2017.

[19] M. Aliakbari, F. A. Amoli. (2016). The effects of teacher empowerment on teacher commitment and student achievement, Mediterranean Journal of Social Sciences, Vol. 7, No.4, 649-657, 2016.

[20] M. N. Jabbar, F. Husin. (2018). Effect of organizational leadership behavior and empowerment on job satisfaction, Revista de Ciencias Humanas y Sociales, Vol. 16, No.2018, 472-491, 2018.

[21] D. J. Tindowen. (2019). Influence of empowerment on 
teachers' organizational behaviors, European Journal of 1996. Educational Research, Vol. 8, No.2, 617-631, 2019.

[22] J. F. Hair, W. C. Black, B. J. Babin, R. E. Anderson. (2014). Multivariate Data Analysis, 7th ed., Pearson Education Limited, New Jersey, 2014.

[23] Z. Awang, L. S. Hui, N. F. S. Zainudin. (2018). Pendekatan Mudah SEM Structural Equation Modelling, MPWS Rich Resources Sdn. Bhd., Selangor, 2018.

[24] R. B. Kline. (2011). Principles and Practice of Structural Equation Modelling, 3rd ed., The Guilford Press, New York, 2011.

[25] R. P. Mc Donald, M. H. R. Ho. (2002). Principles and practice in reporting statistical equation analyses, Psychological Methods, Vol. 7, No,1, 64-82, 2002.

[26] M. Byrne. (1998). Structural Equation Modelling with LISREL, PRELIS and SIMPLIS: Basic Concepts, Applications and Programming, Lawrence Erlbaum Associates, Mahwah, New Jersey, 1998.

[27] R. C. MacCallum, M. W. Browne, H. M. Sugawara. (1996). Power analysis and determination of sample size for covariance structure modelling, Psychological Methods, Vol. 1, No.2, 130-149, 1996.

[28] T. A. Brown. (2006). Confirmatory Factor Analysis for Applied Research, Guilford Press, New York,

[29] J. Miles, M. Shevlin. (2007). A time and a place for incremental fit indices. Personality and Individual Differences, Vol. 42, No.5, 869-874, 2007.

[30] L. T. Hu, P. M. Bentler. (1999). Cutoff criteria for fit indexes in covariance structure analysis: Conventional criteria versus new alternatives, Structural Equation Modelling, Vol. 6, No.1, 1-55, 1999.

[31] R. W. Brislin. (1970). Back-translation for cross-cultural research, Journal of Cross Cultural Psychology, Vol. 1, No.3, 185-216, 1970.

[32] M. W. Browne, R. Cudeck. (1993). Alternative ways of assessing model fit. In K. A. Bollen, J. S. Long (Eds.), Testing Structural Equation Models (pp. 136-162), Sage, Newbury Park, CA, 1993.

[33] H. W. Marsh, D. Hocevar. (1985). Application of confirmatory factor analysis to the study of self-concept: First and higher order factor models and their invariance across groups, Psychological Bulletin, Vol. 97, No.3, $562-582,1985$.

[34] M. Z. Mustafa, M. N. Nordin, A. R. Abdul Razzaq. (2020). Structural equation modelling using AMOS: Confirmatory factor analysis for taskload of special education integration program teachers, Universal Journal of Educational Research, Vol. 8, No.1, 127-133, 2020.

[35] T. F. Tengku Ariffin, R. A. Hashim, N. Yusof. (2014). Proximal and distal outcomes of organizational socialization among new teachers: A mediation analysis, Teacher Development, Vol. 18, No.2, 163-176, 2014.

[36] B. Klecker, W. E. Loadman. (1996). Dimesions of Teacher Empowerment: Identifying New Roles for Classroom Teachers in Restructuring Schools. Annual Meeting of the Mid-South Educational Research Association, Tuscaloosa, 